\title{
A Double-Blind, Placebo-Controlled Trial of Oral Human Immunoglobulin for Gastrointestinal Dysfunction in Children with Autistic Disorder
}

\author{
Benjamin L. Handen - Raun D. Melmed - Robin L. Hansen • \\ Michael G. Aman · David L. Burnham · Jon B. Bruss • \\ Christopher J. McDougle
}

Published online: 16 January 2009

(c) The Author(s) 2009. This article is published with open access at Springerlink.com

\begin{abstract}
Controversy exists regarding the extent and possible causal relationship between gastrointestinal symptoms and autism. A randomized, double-blind, placebo-controlled, parallel groups, dose-ranging study of oral, human immunoglobulin (IGOH 140, 420, or $840 \mathrm{mg} /$ day) was utilized with 125 children (ages 2-17 years) with autism and persistent GI symptoms. Endpoint analysis revealed no significant differences across treatment groups on a modified global improvement scale (validated in irritable bowel syndrome studies), number of daily bowel
\end{abstract}

\author{
B. L. Handen $(\square)$ \\ University of Pittsburgh School of Medicine, 1011 Bingham St., \\ Pittsburgh, PA 15203, USA \\ e-mail: handenbl@upmc.edu \\ R. D. Melmed \\ Southwest Autism Research and Resource Center, Scottsdale, \\ AZ, USA \\ R. L. Hansen \\ M.I.N.D. Institute, University of California, Davis, Sacramento, \\ CA, USA \\ M. G. Aman \\ The Nisonger Center, Ohio State University, Columbus, $\mathrm{OH}$, \\ USA \\ D. L. Burnham · J. B. Bruss \\ PediaMed Pharmaceuticals, Inc., Florence, KY, USA \\ C. J. McDougle \\ Indiana University School of Medicine, Indianapolis, IN, USA \\ Present Address: \\ D. L. Burnham \\ PRA International, Burlington, KY, USA \\ J. B. Bruss \\ Alarus Developmental International, Cincinnati, OH, USA
}

movements, days of constipation, or severity of problem behaviors. IGOH was well-tolerated; there were no serious adverse events. This study demonstrates the importance of conducting rigorous trials in children with autism and casts doubt on one GI mechanism presumed to exert etiological and/or symptomatic effects in this population.

Keywords Autism · Gastrointestinal symptoms · Oral human immunoglobulin

\section{Introduction}

While the etiology of autism is unknown, the disorder is thought to result from multiple genetic and environmental factors. There is some preliminary evidence suggesting that exposure to viral or bacterial pathogens may play a role in triggering the disorder in a small subgroup of individuals with autism (Folstein and Rutter 1997; Sandler et al. 2000; Singh et al. 1998; Sweeten et al. 2004; van Gent et al. 1997). One prominent theme that has appeared in the literature as well as in the popular press has been a possible "gut-brain" linkage in a subgroup of children. Interestingly, gastrointestinal (GI) abnormalities are frequently reported in children with autism, although the reported prevalence of GI symptoms in these subjects varies widely (Horvath and Perman 2002; Molloy and Manning-Courtney 2003; Taylor et al. 2002; Valicenti-McDermott et al. 2006). Most of these studies have relied on either parental recall or medical records review and are often subject to referral bias (as most studies have only included children with autism who were referred with GI problems). A review of this literature by Kuddo and Nelson (2003) found no available reports of the prevalence of GI symptoms in a representative sample of children with autism and 
appropriate controls and to date there has been no published, well designed prospective study to determine the incidence and prevalence. Despite a lack of controlled data, many clinicians and researchers within the autism field feel that nutritional and GI issues remain a significant concern for this population (Erickson et al. 2005). In fact, the Autism Treatment Network (funded by Autism Speaks), will be implementing a standardized autism diagnostic protocol that emphasizes the need to assess often overlooked co-morbid medical disorders. GI disorders are among the required areas that will be addressed in this assessment.

As the etiology of autism is unknown, there are many unapproved and unproven treatments offered for these patients, such as heavy metal detoxification and various nutritional therapies (Aman 2005). There is little, if any, evidence-based support for these interventions in autism, although there are anecdotal reports on their effectiveness (Christison and Ivany 2006; Levy and Hyman 2003). Treatments to alleviate GI symptoms present in some children with autism are often recommended based upon suggestions that the underlying GI dysfunction has histopathological and immunological characteristics that resemble inflammatory bowel disease (IBD) (Furlano et al. 2001; Horvath et al. 1999; Torrente et al. 2002). However, the relationship between IBD and autism remains tenuous (Erickson et al. 2005).

Despite this controversy, there are claims of a specific GI immunopathology associated with autism that suggest treatments such as oral immunoglobulin, may prove to be effective in treating the GI dysfunction in children with autism (Borowitz and Saulsbury 1991; Guarino et al. 1994; Losonsky et al. 1985; Tacket et al. 1988; 1992; Tjellstrom et al. 1993, 1997). There is some evidence to support the use of oral immunoglobulin in other GI disorders, but in many of these disorders the etiology and pathophysiology are better characterized, such as rotavirus diarrhea, chronic diarrhea in children with short-gut syndrome, and pseudomembranous colitis due to Clostridium difficile. The use of immunoglobulin has not been studied in well controlled trials in patients with IBS. Oral immunoglobulin appears to be well-tolerated with no serious side effects reported in low birth weight neonates (Barnes et al. 1982), children and adults with serious intestinal infections (Borowitz and Saulsbury 1991; Guarino et al. 1994; Losonsky et al. 1985; Tacket et al. 1988; 1992; Tjellstrom et al. 1993, 1997), and in healthy adult volunteers (Bogstedt et al. 1995).

Schneider et al. (2006) previously conducted an 8 week prospective open-label pilot study using oral immunoglobulin (Oralgam) in 12 children with autism and persistent GI dysfunction. Nine of 12 subjects completed the pilot study. Eight of the 9 subjects had significant improvement in GI signs and symptoms and 6 of 9 met criteria for clinical response or remission. The high percentage of responders and the apparent sustained effect (4 weeks) after end of therapy suggested the possibility of a treatment effect beyond the anticipated high placebo effect. Based upon these preliminary results, a doubleblind, placebo-controlled trial was designed. The aim of this study was to determine whether a 12 week treatment with oral immunoglobulin would result in a significant, dose-dependent reduction from baseline in GI signs and symptoms in a group of 125 children with autism and GI dysfunction in comparison to placebo. We hypothesized that oral immunoglobulin would reduce clinical signs and/ or symptoms of GI dysfunction associated with autism. In addition, we hypothesized that there would be secondary behavioral improvement (e.g., decreased agitation and irritability) in those children who were responders to treatment.

\section{Methods}

This was a randomized, double-blind, placebo-controlled, parallel groups, dose-ranging study conducted across 12 centers in the United States. Local institutional review boards or a central IRB (Western IRB, Seattle WA, USA) approved the protocol. Written, informed consent was obtained from each subject's parent or guardian. Male and female subjects 2-17 years of age inclusive were recruited for the study. Following a 2 week screening period, subjects were randomized to treatment with placebo or oral human immunoglobulin (IGOH; Oralgam) 140, 420, or $840 \mathrm{mg} /$ day for 12 weeks. Each capsule contained $140 \mathrm{mg}$ of IGOH or placebo and was administered in divided doses of 3 capsules in the morning and 3 capsules in the evening. IGOH consisted of IVIG in $60 \%$ sucrose (stabilizer) lyophilized into a white powder. Placebo consisted of sucrose and was similar in appearance, taste, and consistency to the active treatment. Patients unable to swallow capsules were allowed to open the capsules and sprinkle the powder in liquid or on food. The dosing was based on results from an uncontrolled pilot study (Schneider et al. 2006) showing what appeared to be some efficacy and a sustained effect with a $420 \mathrm{mg} /$ day dose of IGOH. A review of the literature suggested that we could expect up to $70 \%$ of the IGOH to survive functional and intact through the GI tract. The $140 \mathrm{mg} /$ day dose was included in the current study to determine if similar effects could be obtained with less medication. The $840 \mathrm{mg} /$ day condition was included to determine if a higher dose might lead to greater clinical benefit. All doses were made in multiples of $140 \mathrm{mg}$, as this was the maximum amount that could be placed in a capsule. A computerized system was used to assign and verify 1:1:1:1 randomization, with subjects 
balanced by site and by age (2-11 years and $12-17$ years, inclusive).

Subjects meeting diagnostic criteria for autism per DSM-IV (APA 2000) based on history and examination by clinicians experienced in the diagnosis of autism, and corroborated by standard cutoff scores on the Autism Diagnostic Interview-Revised (ADI-R) (Lord et al. 1994), were eligible for inclusion. Additional inclusion criteria included a clinician Clinical Global Impression scale of Severity (of autistic symptoms) of $\geq 3$ (Arnold et al. 2000) and a history of chronic, persistent GI disturbance based on Rome II Criteria for the diagnosis of irritable bowel syndrome. These criteria included GI disturbance of $\geq 6$ weeks duration, which did not need to be consecutive, during the last 3 months of either (1) constipation predominant (defined as $\leq 2$ bowel movements (BM) per week described as lumpy or hard), (2) diarrhea predominant (defined as $\geq 3$ loose $\mathrm{BM} /$ day or $\geq 1$ watery $\mathrm{BM} /$ day), or (3) alternating periods of constipation and diarrhea as defined above. In addition, at least one of the following needed to be present: abnormal gaseousness, bloating, or symptoms of moderateto-severe abdominal pain or discomfort. Prior to entry, each subject's parent or caregiver agreed to no elective changes in medication, diet intervention, or behavioral therapy for the duration of the study. GI symptoms were confirmed during a 2 week baseline, during which daily data were entered by the parent using a Palm Pilot (which immediately downloaded entries into a central database).

Exclusion criteria included evidence of a GI infection based on stool laboratory tests at baseline, a known diagnosis of other GI pathology, current use of antibiotics or antifungal medications, chelation therapy, medication affecting GI transit (stool softeners and bulking agents were permitted if constant doses were used for $\geq 30$ days prior to the screening visit and no changes in dosing was planned during the course of the study), changes in diet intervention within 30 days prior to the screening visit, or changes in alternative medical therapies. Alternative medical therapies were permitted (e.g., gluten-casein free diets, vitamin supplements) as long as constant doses had been used for $\geq 30$ days prior to the screening visit and no changes were made during the study. Treatment with psychotropic medication was allowed only if taken in a stable dose and employed for $\geq 30$ days prior to the screening visit (with the exception of fluoxetine which must have been taken in a stable dose and employed for $\geq 5$ weeks prior to the screening visit). Additional exclusion criteria included a DSM-IV diagnosis of a pervasive developmental disorder other than autism, evidence of a seizure disorder, Fragile $\times$ syndrome, Tuberous Sclerosis Complex, liver or pancreatic disease, cystic fibrosis, chronic infection, previous GI surgery with the exception of fundoplication, appendectomy, gastrostomy, endoscopy, pyloromyotomy, or herniorraphy, pregnancy, participation in another investigational study within 60 days prior to the screening visit, $\operatorname{IgA}$ deficiency (serum $\operatorname{IgA}<5 \mathrm{mg} / \mathrm{dl}$ ), a history of severe hypersensitivity to human immunoglobulin, treatment with any human immunoglobulin and/or immunoglobulin products within 90 days prior to the screening visit, or any concurrent medication that would compromise tolerance of drug or compliance with the protocol. The above information was obtained via parental report, with the exception of the diagnosis of autism (which was confirmed by study staff). During the 2 week screening period additional exclusion criteria were applied for entry into the double-blind treatment period. Subjects were not eligible for study participation if any of the following occurred: clinically significant abnormal laboratory test values, failure of parent or guardian to record at least 11 of 14 days of daily diary assessments or the weekly assessments during the screening period, a GI Symptoms Score of $<5$ for week-2 and/or week-1 of the screening period, a MGIS score of moderately or substantially improved during week-2 and/or week-1 of the screening period, parent or guardian's inability or unwillingness to follow directions or inability to understand how to use the electronic diary data entry system.

The MGIS was based upon an assessment tool used for IBS patients and validated in controlled IBS trials (Gordon et al. 2003). The MGIS utilizes a 7-point Likert scale answering the question: "Please consider how your son or daughter felt this past week in regard to symptoms of abdominal discomfort, pain and altered bowel habit. Compared to the way he or she usually felt before entering the study, are his or her GI symptoms this past week substantially worse, moderately worse, somewhat worse, unchanged, somewhat improved, moderately improved, or substantially improved?" Each subject was considered a responder if he or she was moderately improved or substantially improved on at least 2 of the last 4 assessments or somewhat improved for all of the last 4 assessments of the MGIS. The GI Symptoms Score included variables of stool frequency, stool consistency, abdominal pain/discomfort, and gas and/or bloating (instruments available on request from co-author, RM).

The following dependent measures were collected:

1. MGIS: The MGIS score served as the primary endpoint of the study. The primary endpoint was the clinical response to study treatment after 12 weeks of therapy in the intent-to-treat population (ITT). The MGIS was completed by parents and used to assess weekly status in GI signs and symptoms.

2. Weekly GI Symptoms Assesment: In addition to the MGIS as the primary endpoint comparing the patient's condition to baseline, a weekly assessment using MGIS 
was also used to compare the patient's condition to the previous week. A weekly daily GI symptom score was also obtained from parents for the following: (a) abdominal pain/discomfort using a 7-point Likert scale, (b) normalized bowel habit using a 7-point Likert scale and (c) satisfaction with resolution of GI symptoms using a 4-point Likert scale. Data were entered every evening via the electronic diary.

3. Daily GI Symptom Score: Daily GI symptoms were assessed, including number of bowel movements, consistency and intensity of abdominal discomfort/pain, intensity of gas/bloating, all using 7-point Likert scales. Data were entered every evening via the electronic diary. 4. Behavioral Measures: The presence of and change in the level of maladaptive behaviors was assessed using two measures. The Aberrant Behavior Checklist (ABC; Aman et al. 1985a) was completed at each study visit (monthly) and is a standardized instrument comprising five subscales designated as (a) Irritability (15 items); (b) Lethargy/Social Withdrawal (16 items); (c) Stereotypic Behavior (7 items); (d) Hyperactivity, Noncompliance (16 items); and (e) Inappropriate Speech (4 items). It is sensitive to psychotropic intervention and has very good reliability and validity (Aman et al. 1985b). A Clinical Global Impression of Improvement (CGI-I; Guy 1976a, b) was completed at each study visit by both parent and clinician, based upon the severity of behavioral problems. The CGI-I is often utilized in studies of psychotropic drugs and often serves as the main outcome measure in pharmacological trials (Aman and Pearson 1999). Improvement is scored on a 7-point scale which ranges from "very much improved" (1), through "no change" (4), to "very much worse" (7). CGI-I ratings were based on changes in the child's associated maladaptive behaviors, plus autism symptomatology.

5. General Safety and Tolerability: Safety and tolerability were monitored by physical examination (performed at screening, baseline and every 4 weeks) and clinical laboratory tests (performed at screening and Week 12). Additionally, adverse experience assessments were recorded at all visits. An adverse event (AE) was defined as any untoward medical occurrence or unintended change from the subject's baseline (pre-treatment) condition, including concurrent illness, that occurred during the course of the study, whether considered related to study treatment or not.

\section{Data Analysis}

The primary endpoint (MGIS score at week 12) was analyzed using a Cochran-Armitage test for trend. Linearity was first tested using a logistic regression analysis in which both linear and quadratic terms for dose were included. Proof of non-linearity was established when the quadratic term was statistically significant. When the quadratic term was not significant, the Cochran-Armitage test was used to assess the primary outcome, with logistic regression used in any secondary analyses requiring the inclusion of covariates. Efficacy was assessed in the ITT population. A second, per protocol, subject analysis was performed on individuals who met the criteria for being clinically evaluable (CE). The CE population was defined as all randomized subjects who fulfilled the following criteria: $\geq 8$ weeks of double-blind treatment, compliance of $\geq 75 \%$ of prescribed study medication, $<4$ consecutive days of missed therapy during the treatment period; compliance with the requirement for daily diary entry, $\geq 14$ days of entry during the last 4 weeks of treatment; and no use of disallowed medication affecting GI motility during the last 4 weeks of treatment. All statistical tests were two-sided with a $p$ value $\leq .05$ considered statistically significant. The sample size was based upon the results of our previous pilot study and was pre-determined assuming a variance in placebo response rate between 20 and 40\%. A sample size of 30 subjects per treatment group was predicted to provide $80 \%$ statistical power to detect a significant dose-response relationship involving the following absolute differences in response rates relative to placebo: $4-6 \%$ for $140 \mathrm{mg} / \mathrm{day}$, $14-17 \%$ for $420 \mathrm{mg} / \mathrm{day}$, and $32-33 \%$ for $840 \mathrm{mg} / \mathrm{day}$. Furthermore, we expected that 96 subjects $(80 \%)$ would be CE.

\section{Results}

A total of 192 subjects were screened for eligibility, 125 subjects were randomized (ITT), 100 (80\%) subjects completed the study, and $82(65.6 \%)$ subjects were CE. The primary reasons for screen failure were (1) GI symptom score less than 5 during the screening period and (2) parent/caregiver withdrawal of consent. A similar number of withdrawals occurred in each study group: $140 \mathrm{mg} /$ day, $n=5 ; 420 \mathrm{mg} /$ day, $n=8 ; 840 \mathrm{mg} /$ day, $n=7$; placebo, $n=5$. The most common reason for discontinuation was the withdrawal of consent by the subject or guardian (10 of 25 discontinued subjects). Termination due to adverse events was the second most common reason for discontinuing the study (8 of 25 discontinued subjects). Patient demographics were similar across all treatment groups, although within each treatment group, substantially more males, Caucasians, and children 2-11 years of age were enrolled (Table 1). For reference, regression-onset of autistic symptoms was defined as a parental report of a sudden regression or plateau of the child's language, social, and play skills (based upon the results of the regression 
Table 1 Patient demographicsITT population

\begin{tabular}{|c|c|c|c|c|}
\hline & Placebo & $\begin{array}{l}\text { IGOH } \\
140 \mathrm{mg} / \text { day }\end{array}$ & $\begin{array}{l}\text { IGOH } \\
420 \mathrm{mg} / \text { day }\end{array}$ & $\begin{array}{l}\text { IGOH } \\
840 \mathrm{mg} / \text { day }\end{array}$ \\
\hline$N$ & 31 & 32 & 31 & 31 \\
\hline \multicolumn{5}{|l|}{ Age, years } \\
\hline Mean \pm SD & $6.2 \pm 3.3$ & $7.4 \pm 3.1$ & $8.0 \pm 4.1$ & $7.6 \pm 3.5$ \\
\hline Range & $2-14$ & $3-13$ & $2-17$ & $3-13$ \\
\hline \multicolumn{5}{|l|}{ Age, $n(\%)$} \\
\hline $2-11$ years & $27(87.1)$ & $28(87.5)$ & $27(87.1)$ & $27(87.1)$ \\
\hline $12-17$ years & $4(12.9)$ & $4(12.5)$ & $4(12.9)$ & $4(12.9)$ \\
\hline \multicolumn{5}{|l|}{ Gender, $n(\%)$} \\
\hline Male & $25(80.6)$ & $28(87.5)$ & $28(90.3)$ & $26(83.9)$ \\
\hline Female & $6(19.4)$ & $4(12.5)$ & $3(9.7)$ & $5(16.1)$ \\
\hline \multicolumn{5}{|l|}{ Race, $n(\%)$} \\
\hline Caucasian & $23(74.2)$ & $28(87.5)$ & $27(87.1)$ & $27(87.1)$ \\
\hline African-American & $2(6.5)$ & $1(3.1)$ & $0(0)$ & $0(0)$ \\
\hline Asian & $0(0)$ & $1(3.1)$ & $0(0)$ & $0(0)$ \\
\hline Hispanic & 4 (12.9) & $2(6.3)$ & $2(6.5)$ & $1(3.2)$ \\
\hline Other & $2(6.5)$ & $0(0)$ & $2(6.5)$ & $3(9.7)$ \\
\hline \multicolumn{5}{|c|}{ Predominant bowel pattern, $n(\%)$} \\
\hline Diarrhea & $14(45.2)$ & $11(34.4)$ & $9(29.0)$ & $15(48.4)$ \\
\hline Constipation & $12(38.7)$ & $20(62.5)$ & $20(64.5)$ & $11(35.5)$ \\
\hline Alternating & $5(16.1)$ & $1(3.1)$ & $2(6.5)$ & $5(16.1)$ \\
\hline \multicolumn{5}{|c|}{ Regression-onset of autistic symptoms, $n(\%)$} \\
\hline No & $10(32.3)$ & $14(43.8)$ & $11(35.5)$ & $10(32.3)$ \\
\hline Yes & $21(67.7)$ & $18(56.3)$ & $20(64.5)$ & $21(67.7)$ \\
\hline
\end{tabular}

section of the ADI-R). Similar to the ITT population, the CE population had comparable patient demographics within each treatment group (for brevity, data not shown).

There was no significant difference between placebo and any active dose of IGOH in the primary endpoint, overall clinical response to treatment based on MGIS score at week 12 (Fig. 1), in the ITT population (140 mg/day, $p=.39 ; 420 \mathrm{mg} /$ day, $p=.19 ; 840 \mathrm{mg} /$ day, $p=.44)$. Additionally, there was no significant benefit of all active treatments combined compared with placebo $(p=.22)$ nor was there an effect of increasing IGOH doses compared to placebo using a trend analysis (Cochran-Armitage doseresponse trend $p=0.52$ ). Similar results were observed for the CE population. There was also no difference in the time to clinical response in either the ITT or CE population ( $p=.27-.33$, respectively; data not shown). The clinical response was also evaluated by subgroups, including age group, predominant bowel type, and subjects with regression-onset of autistic symptoms. Table 2 shows that (a) in subjects 2-11 years of age, (b) 12-17 years of age, or (c) with regression-onset of autistic symptoms, there was no significant treatment effect (based upon MGIS score) in the ITT population ( $p=.36, .58, .85$, respectively). There was also no significant difference in clinical response to treatment by predominant bowel type in the ITT population (diarrhea, $p=.69 ;$ constipation, $p=.22$; alternating, $p=.79)$ Similar results were obtained from the CE population (data not shown). No site differences were found in regard to either randomization or treatment effects.

Gastrointestinal signs and symptoms uniquely relevant to the study participants were also assessed. IGOH, compared with placebo, did not demonstrate any beneficial effect in any measurement of GI symptoms. In each measurement, global assessment of abdominal pain or discomfort, global assessment of bowel habit, and satisfaction with resolution of GI symptoms (Fig. 2), there was a trend for improvement in GI signs and symptoms throughout the study, but there was no apparent difference between treatments. Finally, none of the ABC subscales revealed any significant beneficial effect of $\mathrm{IGOH}$ compared with placebo, although the overall symptom scores improved (decreased) during the treatment period for all treatment groups.

Each subject's improvement in problem behavior was also assessed by both the clinician and the parent (Table 3). At week 12 there was no significant treatment effect in physician CGI-I scores $(p=.50)$. Additionally, there was no difference in physician CGI-I scores at Week 12 by age group (2-11 years of age, $p=.60 ; 12-17$ years of age, $p=.32$ ) or by bowel habit (diarrhea predominant, 


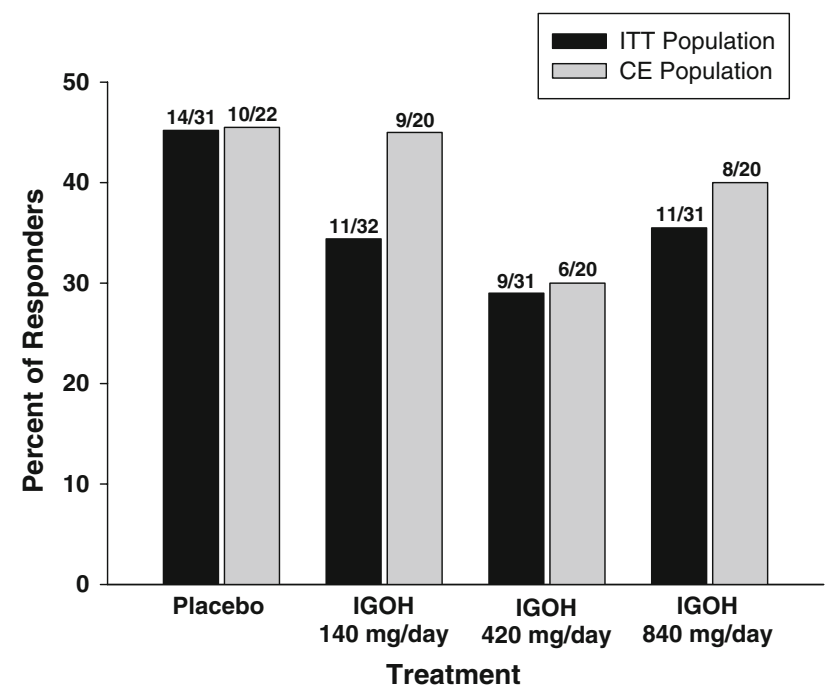

Fig. 1 Clinical response to treatment at week 12 as assessed by the MGIS. Intent-to-treat (ITT) population overall treatment effect, $p=.52$, clinically evaluable (CE) population overall treatment effect, $p=.59$ ( $p$ values are based upon Cochran-Armitage test for a dose-response trend). Each subject was considered a responder if he or she was moderately improved or substantially improved on at least 2 of the last 4 assessments or somewhat improved for all of the last 4 assessments of the MGIS

$p=.88$; constipation predominant, $p=.32$; alternating, $p=.44)$. Conversely, the overall parent CGI-I score at Week 12 revealed a significant difference $(p=.047)$. However, this effect was due to the improvement in the placebo-treated subjects $(57.1 \%$ reported being very much improved or much improved). Analysis of the parent CGI-I

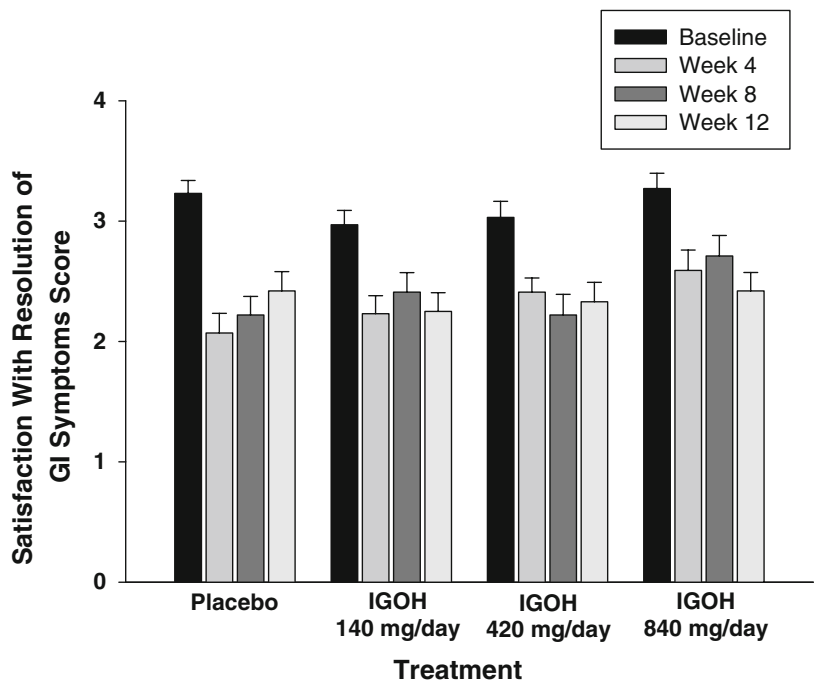

Fig. 2 Satisfaction with resolution of GI symptoms in the ITT population. Satisfaction with resolution of GI symptoms: 1 (very satisfied), 2 (somewhat satisfied), 3 (somewhat dissatisfied), 4 (very dissatisfied). No treatment effect. Values reported as mean \pm standard error

scores by predominant bowel habit revealed no significant treatment effect in the diarrhea predominant subgroup $(p=.28)$ or alternating subgroup $(p=.28)$, yet a significant placebo effect was observed in subjects in the constipation predominant subgroup (63.6\% of subjects very much improved or much improved, $p=.03$ ).

Treatment with IGOH was generally well-tolerated. The majority of subjects $(\geq 74.2 \%)$ reported $\geq 1$ treatment-
Table 2 Clinical response by subgroup at endpoint in the ITT population

\footnotetext{
* $p$ values reported as overall treatment effect via CochranArmitage test for a doseresponse trend (based upon MGIS scores at week 12). There was also no significant treatment effect in pairwise comparisons of each IGOH dose versus placebo $(p>.09)$
}

\begin{tabular}{|c|c|c|c|c|c|}
\hline & Placebo & $\begin{array}{l}\text { IGOH } \\
140 \mathrm{mg} / \text { day }\end{array}$ & $\begin{array}{l}\text { IGOH } \\
420 \mathrm{mg} / \text { day }\end{array}$ & $\begin{array}{l}\text { IGOH } \\
840 \mathrm{mg} / \text { day }\end{array}$ & $p$ value* \\
\hline \multicolumn{6}{|c|}{ Predominant bowel pattern-diarrhea } \\
\hline Responder & $5 / 14$ & $3 / 11$ & $2 / 9$ & $6 / 15$ & \multirow[t]{2}{*}{0.69} \\
\hline Non-responder & $9 / 14$ & $8 / 11$ & $7 / 9$ & $9 / 15$ & \\
\hline \multicolumn{6}{|c|}{ Predominant bowel pattern-constipation } \\
\hline Responder & $7 / 12$ & $7 / 20$ & $7 / 20$ & $3 / 11$ & \multirow[t]{2}{*}{0.22} \\
\hline Non-responder & $5 / 12$ & $13 / 20$ & $13 / 20$ & $8 / 11$ & \\
\hline \multicolumn{6}{|c|}{ Predominant bowel pattern-alternating } \\
\hline Responder & $2 / 5$ & $1 / 1$ & $0 / 2$ & $2 / 5$ & \multirow[t]{2}{*}{0.79} \\
\hline Non-responder & $3 / 5$ & $0 / 1$ & $2 / 2$ & $3 / 5$ & \\
\hline \multicolumn{6}{|c|}{ Subjects with regression-onset of autistic symptoms } \\
\hline Responder & $9 / 21$ & $6 / 18$ & $7 / 20$ & $9 / 21$ & \multirow[t]{2}{*}{0.85} \\
\hline Non-responder & $12 / 21$ & $12 / 18$ & $13 / 20$ & $12 / 21$ & \\
\hline \multicolumn{6}{|c|}{ Subjects $2-11$ years of age } \\
\hline Responder & $13 / 27$ & $9 / 28$ & $7 / 27$ & $9 / 27$ & \multirow[t]{2}{*}{0.36} \\
\hline Non-responder & $14 / 27$ & $19 / 28$ & $20 / 27$ & $18 / 27$ & \\
\hline \multicolumn{6}{|c|}{ Subjects $12-17$ years of age } \\
\hline Responder & $1 / 4$ & $2 / 4$ & $2 / 4$ & $2 / 4$ & \multirow[t]{2}{*}{0.58} \\
\hline Non-responder & $3 / 4$ & $2 / 4$ & $2 / 4$ & $2 / 4$ & \\
\hline
\end{tabular}


Table 3 Overall clinical global impression of improvement at week 12

\begin{tabular}{|c|c|c|c|c|}
\hline & Placebo & IGOH $140 \mathrm{mg} /$ day & IGOH $420 \mathrm{mg} /$ day & IGOH $840 \mathrm{mg} /$ day \\
\hline Physician evaluation, $n(\%)^{\mathrm{a}, \mathrm{b}}$ & $28(100)$ & $29(100)$ & $26(100)$ & $28(100)$ \\
\hline Very much or much improved & $11(39.3)$ & $3(10.3)$ & $9(34.6)$ & $5(17.9)$ \\
\hline Minimally improved or unchanged & $15(53.6)$ & $25(86.2)$ & $14(53.9)$ & $21(75.0)$ \\
\hline Minimally, much or very much worse & $2(7.1)$ & $1(3.4)$ & $3(11.5)$ & $2(7.1)$ \\
\hline Parent evaluation, $n(\%)^{\mathrm{a}, \mathrm{c}}$ & $29(100)$ & $29(100)$ & $26(100)$ & $28(100)$ \\
\hline Very much or much improved & $16(55.2)$ & $6(20.7)$ & $12(46.2)$ & $7(25.0)$ \\
\hline Minimally improved or unchanged & $12(41.4)$ & $21(72.4)$ & $12(46.2)$ & $17(60.7)$ \\
\hline Minimally, much, or very much worse & $1(3.4)$ & $2(6.9)$ & $2(7.6)$ & $4(14.3)$ \\
\hline
\end{tabular}

${ }^{a}$ Only patients who were clinically evaluable (CE) were included in the analysis

b There was no statistically significant difference in the physician CGI-I among treatment groups $(p=.50)$

${ }^{c}$ There was a statistically significant difference in the parent CGI-I among treatment groups $(p=.047)$. This was primarily due to the large improvement in the placebo group

emergent $\mathrm{AE}$ and there was no difference between treatment groups in the number of subjects with $\geq 1$ treatmentemergent $\mathrm{AE}(140 \mathrm{mg} /$ day, $77.4 \%$; $420 \mathrm{mg} / \mathrm{day}, 74.2 \%$; $840 \mathrm{mg} /$ day, $74.2 \%$; placebo, $80.6 \%$ ). Furthermore, there were no treatment-emergent serious AEs and few subjects discontinued the study due to AEs $(140 \mathrm{mg} /$ day, $n=2$; $420 \mathrm{mg} /$ day, $n=2 ; 840 \mathrm{mg} /$ day, $n=3$; placebo, $n=1$ ). The most common treatment-emergent AEs by organ system class were related to infections and infestations, GI disorders, and psychiatric disorders (Table 4). Within the infection and infestations organ system class, the most common AEs were viral gastroenteritis (8 subjects) and bronchitis (4 subjects). The most frequent GI disorder AEs were diarrhea (21 subjects), constipation ( 9 subjects), and vomiting (7 subjects). Treatment-related AEs were also assessed with no difference noted among treatment groups.

\section{Discussion}

Variable rates of gastrointestinal abnormalities have been reported in children with autism. It is unknown if there is a pathophysiological relationship between the two or if they are unrelated, co-existing disorders in a subgroup of these children. The literature suggests a possible link between the GI mucosal immune system, GI dysfunction, and autism, but this link remains controversial and the data are far from conclusive (Ashwood et al. 2003; Linday et al. 2001;

Table 4 Adverse events by organ system class in the ITT population

\begin{tabular}{|c|c|c|c|c|c|}
\hline System organ class & $\begin{array}{l}\text { Placebo } \\
n(\%)\end{array}$ & $\begin{array}{l}\text { IGOH } \\
140 \mathrm{mg} / \text { day } \\
n(\%)\end{array}$ & $\begin{array}{l}\text { IGOH } \\
420 \mathrm{mg} / \text { day } \\
n(\%)\end{array}$ & $\begin{array}{l}\mathrm{IGOH} \\
840 \mathrm{mg} / \mathrm{day} \\
n(\%)\end{array}$ & $p$ value \\
\hline Infections and infestations & $16(51.6)$ & $14(45.2)$ & $17(54.8)$ & $15(48.4)$ & 0.89 \\
\hline Gastrointestinal disorders & $9(29.0)$ & $12(38.7)$ & $14(45.2)$ & $10(32.3)$ & 0.56 \\
\hline Psychiatric disorders & $6(19.4)$ & $6(19.4)$ & $5(16.1)$ & $6(19.4)$ & 0.98 \\
\hline Respiratory, thoracic, and mediastinal disorders & $4(12.9)$ & $8(25.8)$ & $5(16.1)$ & $2(6.5)$ & 0.20 \\
\hline Skin and subcutaneous tissue disorders & $3(9.7)$ & $8(25.8)$ & $2(6.5)$ & $2(6.5)$ & 0.06 \\
\hline General disorders and administration site conditions & $2(6.5)$ & $3(9.7)$ & $5(16.1)$ & $1(3.2)$ & 0.32 \\
\hline Nervous system disorders & $0(0)$ & $2(6.5)$ & $2(6.5)$ & $3(9.7)$ & 0.42 \\
\hline Injury, poisoning, and procedural complications & $1(3.2)$ & $2(6.5)$ & $0(0)$ & $3(9.7)$ & 0.32 \\
\hline Investigations & $1(3.2)$ & $1(3.2)$ & $0(0)$ & $2(6.5)$ & 0.56 \\
\hline Metabolism and nutrition disorders & $1(3.2)$ & $1(3.2)$ & $1(3.2)$ & $1(3.2)$ & 1.00 \\
\hline Eye disorders & $0(0)$ & $1(3.2)$ & $2(6.5)$ & $0(0)$ & 0.29 \\
\hline Blood and lymphatic system disorders & $1(3.2)$ & $1(3.2)$ & $0(0)$ & $0(0)$ & 0.57 \\
\hline Renal and urinary disorders & $2(6.5)$ & $0(0)$ & $0(0)$ & $0(0)$ & 0.11 \\
\hline Ear and labyrinth disorders & $0(0)$ & $1(3.2)$ & $0(0)$ & $0(0)$ & 0.39 \\
\hline Immune system disorders & $0(0)$ & $1(3.2)$ & $0(0)$ & $0(0)$ & 0.39 \\
\hline Vascular disorders & $0(0)$ & $0(0)$ & $0(0)$ & $1(3.2)$ & 0.39 \\
\hline
\end{tabular}


Sandler et al. 2000). A prospective, open-label, pilot study of oral, human immunoglobulin demonstrated potential as a possible treatment for children with GI dysfunction associated with autism who had failed traditional medical treatment (Schneider et al. 2006). Based upon those preliminary results, this large, randomized, placebo-controlled trial was conducted to examine the effects of oral immunoglobulin in subjects with GI dysfunction and autism. Twelve weeks of treatment with IGOH $(140,420$, and $840 \mathrm{mg} /$ day) was not superior to placebo in reducing GI signs and symptoms in subjects 2-17 years of age with autism. Analysis of subgroups, such as by age and predominant bowel type, also did not reveal any beneficial effect of IGOH compared with placebo. Furthermore, IGOH was not superior to placebo in improving measures of autistic behavior as assessed by both the physician and the parent.

Although the study was adequately powered and designed to address the primary endpoint of bowel function, we did not detect a beneficial effect of IGOH compared with placebo. Additionally, in an effort to detect any treatment effect by specific population, we performed subgroup analyses. Again, IGOH was not found to be superior to placebo on any of the variables assessed. Thus, not only was there no overall treatment effect, there was not a specific subgroup population within the study that was more responsive to treatment with IGOH. Behavioral concerns, as assessed by the $\mathrm{ABC}$ and clinician and parent CGI-I, tended to improve during the study (i.e., as a function of time), but improvement occurred in all treatment groups and was not dose-related. Overall, there was no significant difference between treatment groups on any of the ABC subscales or on the CGI-I.

We can reasonably assume that the immunoglobulin was reaching the intestinal mucosa, as immunoglobulin has been shown to remain intact when administered orally Losonsky et al. 1985; Tacket et al. 1988). Thus, if the hypotheses were correct, we expected to see indications of a dose-response effect, even if the IgG survival rates were low. Conversely, it was intriguing that the highest doses of IGOH consistently were the least responsive in almost all variables assessed. Thus, it is unlikely that we may have missed a minimally effective dosage for these children. The most parsimonious conclusion is that IGOH was not helpful for these children. Despite the fact the children in this study had substantial GI symptom scores at baseline using validated GI measures, this calls into question whether their GI symptoms shared a single etiology in this group, or whether there is even a single GI condition associated with Autism.

Despite a lack of efficacy, IGOH was well-tolerated. The number of subjects with any AE was similar across all treatment groups. Additionally, there were no subjects with treatment-emergent serious AEs and only eight subjects discontinued the study due to AEs. These findings are in agreement with previous reports examining oral immunoglobulin in neonates (Barnes et al. 1982) and children or adults with serious intestinal infections (Borowitz and Saulsbury 1991; Guarino et al. 1994; Losonsky et al. 1985; Tacket et al. 1988; 1992; Tjellstrom et al. 1993, 1997).

\section{Limitations}

Despite the negative results, the current study is one of the largest, randomized, placebo-controlled, clinical trials conducted within the field of autism. The relatively large sample size in this study allowed for a number of subgroup analyses, as it is possible that children with certain demographic and/or behavioral characteristics might differentially respond to various treatment modalities. The placebo effect of $\sim 40 \%$ is rather high in comparison to other recent autism trials (e.g., Posey et al. 2007; RUPP 2002). One common challenge (and limitation) in conducting studies in non-communicating patients with $\mathrm{AD}$ is the reliance on third-party assessments. While the reports of diarrhea and constipation may be fairly reliable (as they are based upon observable events), ratings of bloating, abdominal pain, etc. are more subjective and inherently less reliable. Another limitation is the challenge of making an accurate diagnosis of autism in children as young as 2 years of age. First, it should be noted that the youngest child randomized was 2 years 4 months of age and that only five (5) subjects under 3 years of age were screened and only 2 of these 5 were randomized. Second, only subjects with diagnoses of autism were enrolled (as opposed to PDD-NOS), making a false positive diagnosis less likely.

An additional potential limitation was the lack of evaluation by a gastroenterologist at baseline who might have detected more specific gastrointestinal issues (e.g., gastroesophageal reflux disease, eosinophilic esophagitis). Also of note was the somewhat low proportion of "completers" (CE) in comparison to the ITT group. The study had rather stringent criteria to be classified as a completer. Hence, those in the ITT group did not necessarily drop out of the study, but simply did not meet CE criteria (e.g., taking $\geq 75 \%$ of prescribed study medication, less than 4 consecutive days of missed doses during the treatment period; compliance with the requirement for daily diary entry). Finally, this group constituted an unusually high rate of children who were classified as experiencing regression of skills during the first years of life (and, therefore, may not be as representative of the autistic population). This determination was based upon parental responses on the ADI-R, which inquires about skill loss across a range of domains. As this group of children all met diagnostic 
criteria for autistic disorder, the rate of reported skill regression might be expected to be greater than that found among children within the entire PDD spectrum. Yet, it is also possible that children with autism who report GI problems are more likely to have experienced a regression in skills.

\section{Clinical Implications}

IGOH does not appear to be an effective treatment for children with autism and GI dysfunction. Additionally, there does not appear to be a subgroup of children with autism for whom such a treatment may be warranted. There is a need in this field to follow promising, open-label findings with well controlled studies. This is especially true in the field of developmental disabilities, where the use of controversial and unproven treatments is frequently the norm. Appropriate treatment for GI dysfunction in children with autism remains an unmet medical need. In the absence of other experimental treatments in research, perhaps the next step to be taken, prior to conducting additional treatment studies, is to more carefully assess and understand possible underlying causes and pathophysiology of the GI dysfunction, including characterization of any immune dysfunction in this population if such exist.

Acknowledgments This study was sponsored by PediaMed Pharmaceuticals, Inc., clinical trials identifier, NCT00110708. We extend a special thank you to parents and caregivers associated with this study. Your time and cooperation was appreciated. We also thank the following investigators for their commitment, time, and leadership to ensure this trial was executed with the utmost scientific rigor: Dr. Paul Hardy, Hardy Health Associates, Hingham, MA; Dr. Michael Johnson, Sarkis Clinical Trials, Gainesville, FL; Dr. Cynthia Molloy, Cincinnati Children's Hospital Medical Center, Cincinnati, OH; Dr. Christopher McDougle, Riley Hospital for Children, Indianapolis, IN; Dr. Gary Stobbe, Autism Spectrum Treatment and Research Center, Seattle, WA; Dr. Tanya Murphy, University of Florida HSC, Gainesville, FL; Dr. Sherie Novotny, Robert Wood Johnson Medical School, Piscataway, NJ; Dr. Nevada Reed, Pediatric Clinical Trials, Akron, OH; Dr. Susan Hyman, University of Rochester Medical Center, Rochester, NY; Dr. Kathryn Ellerbeck, University of Kansas Medical Center, Kansas City, KS; Dr. Cindy Schneider, Center for Autism Research and Education, Phoenix, AZ; Dr. Melissa Kempf, San Antonio, TX; Dr. Adly Thebaud, Medical Research Group of Central Florida, Orange City, FL; Dr. Amy Holmes, Gulf Coast Research, Baton Rouge, LA; Dr. Wendy Daly, Bluegrass Clinical Research, Louisville, KY; Dr. David Duesenberg, Mercy Health Research, St. Louis, MO; Dr. Richard Jackson, Pivotal Research Centers-Detroit, Royal Oak, MI; Dr. James Bradstreet, International Child Development Resource Center, Melbourne, FL. Editorial support was provided by Ed Shifflett, PhD, AlphaRmaxim Healthcare Communications.

Open Access This article is distributed under the terms of the Creative Commons Attribution Noncommercial License which permits any noncommercial use, distribution, and reproduction in any medium, provided the original author(s) and source are credited.

\section{References}

Aman, M. G. (2005). Treatment planning for patients with autism spectrum disorders. The Journal of Clinical Psychiatry, 66(Suppl. 10), 38-45.

Aman, M. G., \& Pearson, D. A. (1999). Monitoring and measuring drug effects. II. Behavioral, emotional, and cognitive effects (Vol. 2, pp. 99-164). New York, NY: Plenum Press.

Aman, M. G., Singh, N. N., Stewart, A. W., \& Field, C. J. (1985a). The aberrant behavior checklist: a behavior rating scale for the assessment of treatment effects. American Journal of Mental Deficiency, 89, 485-491.

Aman, M. G., Singh, N. N., Stewart, A. W., \& Field, C. J. (1985b). Psychometric characteristics of the aberrant behavior checklist. American Journal of Mental Deficiency, 89, 492-502.

American Psychiatric Association. (2000). Diagnostic and statistical manual of mental disorders, 4th ed. text revision (DSM-IV-TR). Washington, DC: American Psychiatric Association.

Arnold, L. E., Aman, M. G., Martin, A., Collier-Crespin, A., Vitiello, B., Tierney, E., et al. (2000). Assessment in multisite randomized clinical trials of patients with autistic disorder: The Autism RUPP Network. Research units on pediatric psychopharmacology. Journal of Autism and Developmental Disorders, 30, 99-111. doi:10.1023/A:1005451304303.

Ashwood, P., Anthony, A., Pellicer, A. A., Torrente, F., Walker-Smith, J. A., \& Wakefield, A. J. (2003). Intestinal lymphocyte populations in children with regressive autism: Evidence for extensive mucosal immunopathology. Journal of Clinical Immunology, 23, 504-517. doi:10.1023/B:JOCI.0000010427.05143.bb.

Barnes, G. L., Doyle, L. W., Hewson, P. H., Knoches, A. M., McLellan, J. A., Kitchen, W. H., et al. (1982). A randomised trial of oral gammaglobulin in low-birth-weight infants infected with rotavirus. Lancet, 1, 1371-1373. doi:10.1016/S0140-6736(82) 92496-5.

Bogstedt, A. K., Nord, C. E., \& Hammarstrom, L. (1995). Lack of effect of orally administered human serum immunoglobulin on the normal human oral and intestinal microflora. European Journal of Clinical Microbiology \& Infectious Diseases, 14, 61-64. doi:10.1007/BF02112623.

Borowitz, S. M., \& Saulsbury, F. T. (1991). Treatment of chronic cryptosporidial infection with orally administered human serum immune globulin. The Journal of Pediatrics, 119, 593-595. doi: 10.1016/S0022-3476(05)82412-6.

Christison, G. W., \& Ivany, K. (2006). Elimination diets in autism spectrum disorders: Any wheat amidst the chaff? Journal of Developmental and Behavioral Pediatrics, 27, S162-S171. doi: 10.1097/00004703-200604002-00015.

Erickson, C. A., Stigler, K. A., Crokins, M. R., Posey, D. J., Fitzgerald, J. F., \& McDougle, C. J. (2005). Gastrointestinal factors in autistic disorder: A critical review. Journal of Autism and Developmental Disorders, 35, 713-727. doi:10.1007/ s10803-005-0019-4.

Folstein, S., \& Rutter, M. (1997). Infantile autism: A genetic study of 21 twin pairs. Journal of Child Psychology and Psychiatry, and Allied Disciplines, 18, 297-321. doi:10.1111/j.1469-7610. 1977.tb00443.x.

Furlano, R. I., Anthony, A., Day, R., Brown, A., McGarvey, L., Thomson, M. A., et al. (2001). Colonic CD8 and gamma delta T-cell infiltration with epithelial damage in children with autism. The Journal of Pediatrics, 138, 366-372. doi:10.1067/mpd. 2001.111323.

Gordon, S., Ameen, V., Bagby, B., Shahan, B., Jhingran, P., \& Carter, E. (2003). Validation of irritable bowel syndrome Global Improvement Scale: an integrated symptom end point for 
assessing treatment efficacy. Digestive Diseases and Sciences, 48, 1317-1323. doi:10.1023/A:1024159226274.

Guarino, A., Canani, R. B., Russo, S., Albano, F., Canani, M. B., Ruggeri, F. M., et al. (1994). Oral immunoglobulins for treatment of acute rotaviral gastroenteritis. Pediatrics, 93, $12-16$.

Guy, W. (1976a). ECDEU Assessment manual of psychopharmacology. Rockville, Md: National Institute of Mental Health USA Department of Health, Education, and Welfare publication (ADM), Psychopharmacology Research Branch, pp. 76-338.

Guy, W. (1976b). Dosage record and treatment emergent symptoms scale, ECDEU assessment manual for psychopharmacology (Revised). USA Department of Health, Education and Human Welfare publication (ADM), (pp. 223-244).

Horvath, K., \& Perman, J. A. (2002). Autism and gastrointestinal symptoms. Current Gastroenterology Reports, 4, 251-258. doi:10.1007/s11894-002-0071-6.

Horvath, K., Papadimitriou, J. C., Rabsztyn, A., Drachenberg, C., \& Tildon, J. T. (1999). Gastrointestinal abnormalities in children with autistic disorder. The Journal of Pediatrics, 135, 559-563. doi:10.1016/S0022-3476(99)70052-1.

Kuddo, T., \& Nelson, K. B. (2003). How common are gastrointestinal disorders in children with autism? Current Opinion in Pediatrics, 15, 339-343. doi:10.1097/00008480-200306000-00020.

Levy, S. E., \& Hyman, S. L. (2003). Use of complementary and alternative treatments for children with autistic spectrum disorders is increasing. Pediatric Annals, 32, 685-691.

Linday, L. A., Tsiouris, J. A., Cohen, I. L., Shindledecker, R., \& DeCresce, R. (2001). Famotidine treatment of children with autistic spectrum disorders: Pilot research using single subject research design. Journal of Neural Transmission, 108, 593-611. doi: $10.1007 / \mathrm{s} 007020170059$.

Lord, C., Rutter, M., \& Le Couteur, A. (1994). Autism diagnosticinterview-revised: A revised version of a diagnostic interview for caregivers of individuals with possible pervasive developmental disorders. Journal of Autism and Developmental Disorders, 24, 659-685. doi:10.1007/BF02172145.

Losonsky, G. A., Johnson, J. P., Winkelstein, J. A., \& Yolken, R. H. (1985). Oral administration of human serum immunoglobulin in immunodeficient patients with viral gastroenteritis. A pharmacokinetic and functional analysis. The Journal of Clinical Investigation, 76, 2362-2367. doi:10.1172/JCI112248.

Molloy, C. A., \& Manning-Courtney, P. (2003). Prevalence of chronic gastrointestinal symptoms in children with autism and autistic spectrum disorders. Autism, 7, 165-171. doi:10.1177/136236130 3007002004.

Posey, D. J., Aman, M. G., McCracken, J. T., Scahill, L., Tierney, E., Arnold, L. E., et al. (2007). Positive effects of methylphenidate on inattention and hyperactivity in pervasive developmental disorders: An analysis of secondary measures. Biological Psychiatry, 61, 538-544. doi:10.1016/j.biopsych.2006.09.028.

Research Units on Pediatric Psychopharmacology Autism Network. (2002). Risperidone in children with autism and serious behavioral problems. The New England Journal of Medicine, 347, 314-321. doi:10.1056/NEJMoa013171.
Sandler, R. H., Finegold, S. M., Bolte, E., Buchanan, C. P., Maxwell, A. P., Väisänen, M., et al. (2000). Short-term benefit from oral vancomycin treatment of regressive-onset Autism. Journal of Child Neurology, 15, 429-435. doi:10.1177/08830738000 1500701.

Schneider, C. K., Medmed, R. D., Enriquez, F. J., Barstow, L. E., Ranger-Moore, J., \& Ostrem, J. A. (2006). Oral human immunoglobulin for children with autism and gastrointestinal dysfunction: A prospective, open-label study. Journal of Autism and Developmental Disorders, 36, 1053-1064. doi:10.1007/ s10803-006-0141-y.

Singh, V. K., Lin, S. X., \& Yang, V. C. (1998). Serological association of measles virus and human herpesvirus- 6 with brain autoantibodies in autism. Clinical Immunology and Immunopathology, 89, 105-108. doi:10.1006/clin.1998.4588.

Sweeten, T. L., Posey, D. J., \& McDougle, C. J. (2004). Autistic disorder in three children with cytomegalovirus infection. Journal of Autism and Developmental Disorders, 34, 583-586. doi:10.1007/s10803-004-2552-y.

Tacket, C. O., Losonsky, G., Link, H., Hoang, Y., Guesry, P., Hilpert, H., et al. (1988). Protection by milk immunoglobulin concentrate against oral challenge with enterotoxigenic Escherichia coli. The New England Journal of Medicine, 318, 1240-1243.

Tacket, C. O., Binion, S. B., Bostwick, E., Losonsky, G., Roy, M. J., \& Edelman, R. (1992). Efficacy of bovine milk immunoglobulin concentrate in preventing illness after Shigella flexneri challenge. The American Journal of Tropical Medicine and Hygiene, 47, 276-283.

Taylor, B., Miller, E., Lingam, R., Andrews, N., Simmons, A., \& Stowe, J. (2002). Measles, mumps, and rubella vaccination and bowel problems or developmental regression in children with autism: Population study. British Medical Journal, 324, 393396. doi:10.1136/bmj.324.7334.393.

Tjellstrom, B., Stenhammar, L., Eriksson, S., \& Magnusson, K. E. (1993). Oral immunoglobulin a supplement in treatment of Clostridium difficile enteritis. Lancet, 341, 701-702. doi:10.1016/0140-6736(93)90477-X.

Tjellstrom, B., Stenhammar, L., Magnusson, K. E., \& Sandqvist, T. (1997). Oral immunoglobulin treatment in Crohn's disease. Acta Paediatrica, 86, 221-223. doi:10.1111/j.1651-2227.1997. tb08873.x. (Oslo, Norway).

Torrente, F., Ashwood, P., Day, R., Machado, N., Furlano, R. I., Anthony, A., et al. (2002). Small intestinal enteropathy with epithelial IgG and complement deposition in children with regressive autism. Molecular Psychiatry, 7, 375-382.

Valicenti-McDermott, M., McVicar, K., Rapin, I., Wershil, B. K., Cohen, H., \& Shinnar, S. (2006). Frequency of gastrointestinal symptoms in children with autistic spectrum disorders and association with family history of autoimmune disease. Journal of Developmental and Behavioral Pediatrics, 27, S128-S136. doi:10.1097/00004703-200604002-00011.

van Gent, T., Heijnen, C. J., \& Treffers, P. D. (1997). Autism and the immune system. Journal of Child Psychology and Psychiatry, and Allied Disciplines, 38, 337-349. doi:10.1111/j.14697610.1997.tb01518.x. 